\title{
Effect of molar mass ratio of monomers on the mass distribution of chain lengths and compositions in copolymers: extension of the Stockmayer theory
}

Citation for published version (APA):

Tacx, J. C. J. F., Linssen, H. N., \& German, A. L. (1988). Effect of molar mass ratio of monomers on the mass distribution of chain lengths and compositions in copolymers: extension of the Stockmayer theory. Journal of Polymer Science, Part A: Polymer Chemistry, 26(1), 61-69. https://doi.org/10.1002/pola.1988.080260106

DOI:

10.1002/pola.1988.080260106

Document status and date:

Published: 01/01/1988

Document Version:

Publisher's PDF, also known as Version of Record (includes final page, issue and volume numbers)

Please check the document version of this publication:

- A submitted manuscript is the version of the article upon submission and before peer-review. There can be important differences between the submitted version and the official published version of record. People interested in the research are advised to contact the author for the final version of the publication, or visit the DOI to the publisher's website.

- The final author version and the galley proof are versions of the publication after peer review.

- The final published version features the final layout of the paper including the volume, issue and page numbers.

Link to publication

\footnotetext{
General rights

- You may freely distribute the URL identifying the publication in the public portal. follow below link for the End User Agreement:

www.tue.nl/taverne

\section{Take down policy}

If you believe that this document breaches copyright please contact us at:

openaccess@tue.nl

providing details and we will investigate your claim.
}

Copyright and moral rights for the publications made accessible in the public portal are retained by the authors and/or other copyright owners and it is a condition of accessing publications that users recognise and abide by the legal requirements associated with these rights.

- Users may download and print one copy of any publication from the public portal for the purpose of private study or research.

- You may not further distribute the material or use it for any profit-making activity or commercial gain

If the publication is distributed under the terms of Article 25fa of the Dutch Copyright Act, indicated by the "Taverne" license above, please 


\title{
Effect of Molar Mass Ratio of Monomers on the Mass Distribution of Chain Lengths and Compositions in Copolymers: Extension of the Stockmayer Theory
}

\author{
J. C. J. F. TACX, Eindhoven University of Technology, Laboratory of \\ Polymer Chemistry, and H. N. LINSSEN, Eindhoven University of \\ Technology, Department of Mathematics; and A. L. GERMAN, \\ Eindhoven University of Technology, Laboratory of Polymer \\ Chemistry, P.O. Box 513,5600 MB Eindhoven, The Netherlands
}

\begin{abstract}
Synopsis
In statistical copolymers, there exists a distribution according to molar mass as well as according to chemical composition. Stockmayer derived distribution functions, describing the relative weight of a particular molar mass and composition interval, assuming equal molar masses of the monomer units. In this article we present an extension of the distribution functions, suited for those cases where the aforementioned assumption is not valid. The final mathematical result is a product of the original Stockmayer distribution function and a correction function, due to the unequality of molar masses. It appears the correction function is dependent on the average composition, the composition deviation, and the ratio of molar masses of the monomers. Furthermore, a three-dimensional representation of distributions has been developed to get insight in the shape of the distributions.
\end{abstract}

\section{INTRODUCTION}

In most cases, the kinetics of a binary copolymerization can be described by the Alfrey-Mayo (AM) model, in which both monomer and ultimate-unit dependent chain-end reactivity are considered. Assuming the AM model to be valid at any arbitrarily chosen conversion, the instantaneous average composition of the copolymer can be predicted by the simple, well-known differential AM model, ${ }^{1}$ according to eq. (1):

$$
\frac{d M_{1}}{d M_{2}}=\frac{r_{1} q+1}{r_{2} / q+1}
$$

where $r_{i}$ is the reactivity ratio of monomer $i, q$ is the molar feed ratio, and $d M_{1} / d M_{2}$ is the copolymer composition.

As a result of the finiteness of the polymer chains, and the statistical character of the monomer addition and polymer termination processes, in copolymers there exists a distribution according to chain length as well as according to chemical composition. A general theory that embraces the problem of the resulting distributions has been formulated by Stockmayer. ${ }^{2}$ The distribution functions predict the relative mass of macromolecules according to chain length and composition, or according to composition irrespective of chain length of the copolymer. 
However, the distribution functions are derived provided that equal molar masses could be assigned to both monomers $M_{1}$ and $M_{2}$. As a consequence, the application of these functions to real copolymers is hampered since in most copolymerizations the molar masses of the monomer units are unequal. Thus, the predictions of the mass distributions become unreliable.

Because of the fundamental importance of the mass distribution functions and because of the recent development of experimental methods to verify the distributions experimentally, ${ }^{3-5}$ we developed functions, similar to the Stockmayer functions, but suited for systems with monomers of unequal molar masses.

The results of recent comparisons of theoretical and experimental distributions cast doubts on the validity of the integrated AM model, ${ }^{5-9}$ especially at high conversion in bulk and emulsion copolymerizations, probably due to a shift of (apparent) $r$ values with conversion. The instantaneously formed product is strongly affected by the anomalous reaction kinetics. Since a comparison of observed and predicted distributions may contribute to the elucidation of anomalous reaction kinetics $^{5}$ it is obvious that a reliable prediction, which also takes into account the proper molar masses, is of primary importance.

These considerations justify the need of our extension of the Stockmayer distribution functions.

\section{Theoretical}

Under the conditions mentioned by Stockmayer, ${ }^{2}$ the distribution functions can be derived. In order to obtain the distribution functions of chain length and compositions in copolymers prepared by radical copolymerization during an infinitisemal small conversion interval, it is necessary to determine the relative mass [ $\left.W_{l}^{\prime}(y) d y\right]$ of macromolecules having length $l$ and compositions between $\left(P_{0}+y\right)$ and $\left(P_{0}+y+d y\right)$. This relative mass is given by eq. (2):

$$
W_{l}^{\prime}(y)=\frac{l m_{l}(y)\left[P M_{1}+(1-P) M_{2}\right] d y}{\sum_{l} l \int_{y} m_{l}(y)\left[P M_{1}+(1-P) M_{2}\right] d y}
$$

where $P_{0}$ is the average composition of the copolymer, $P$ is the composition of individual chains (molefraction $M_{1}$ ), $l$ the degree of polymerization of individual polymer chains, $M_{1}$ and $M_{2}$ the molar masses of the monomers, and $m_{l}(y)$ the concentration of $M_{1}$ radicals with length $l$ and compositions between $\left(P_{0}+y\right)$ and $\left(P_{0}+y+d y\right)$. The prime indicates that the correct molar masses have been taken into account.

In the special case that equal molar masses are assigned to both monomers, eq. (2) reduces to eq. (3).

$$
W(y) d y=\frac{l m_{l}(y) d y}{\sum l \cdot m_{l}}
$$

Stockmayer ${ }^{2}$ converted eq. (3) into a continuous mass distribution function, 
according to eq. (4):

$W(l, y)=\left[\exp (-l / \lambda) \cdot l / \lambda^{2}\right] \cdot\left[\left(1 / 2 \pi P_{0} Q_{0} K\right)^{1 / 2} \cdot \exp \left(-l \cdot y^{2} / 2 P_{0} Q_{0} \cdot K\right)\right]$

where

$$
K=\left[1-4 P_{0} Q_{0}\left(1-r_{1} r_{2}\right)\right]^{1 / 2}
$$

Here $\lambda$ is the number average degree of polymerization, $Q_{0}$ the average molefraction monomer 2 in the instantaneously formed product, and $r_{i}$ the relative reactivity of monomer $i$.

The overall distribution of compositions irrespective of chain length, i.e., the chemical composition distribution (CCD), is found by integration of eq. (4) over all chain lengths $l$, with the following results:

$$
W(y)=\frac{3 d z}{\left(1+z^{2}\right)^{5 / 2}}
$$

where

$$
z^{2}=\frac{\lambda y^{2}}{2 P_{0} Q_{0} K}
$$

and $W(y)$ is the relative mass of macromolecules having compositions between $\left(P_{0}+y\right)$ and $\left(P_{0}+y+d y\right)$.

In those cases where the assumption $M_{1}=M_{2}$ is not fulfilled, similar mass distributions can be determined. Their derivation will be presented.

Equation (2) can be rewritten as eq. (6):

$$
W_{l}^{\prime}(y) d y=\frac{l m_{l}(y)[P+(1-P) k] d y}{\sum_{l} l \int_{y} m_{l}(y)[P+(1-P) k] d y}
$$

Here $k=M_{2} / M_{1}$, the ratio of the molar masses of the monomers. Equation (6) can now be converted into eq. (7) by introducing $P=P_{0}+y$ :

$$
W_{l}^{\prime}(y) d y=\frac{l m_{l}(y)\left[k+P_{0}(1-k)+y(1-k)\right] d y}{\sum_{l} l\left\{(1-k) \int_{y} m_{l}(y) y d y+\left[k+P_{0}(1-k)\right] \int_{y} m_{l}(y) d y\right\}}
$$

Since the number distribution $\left(m_{l}(y)\right)$ of $M_{1}$ radicals with composition deviation $y$ and with chain length $l$ is symmetrical about the composition deviation $y=0,{ }^{2}$ eq. ( 8 ) is valid:

$$
\int_{y} m_{l}(y) y d y=0
$$


As a consequence, the denominator of eq. (7) can be reduced to

$$
\sum_{l} l\left[k+P_{0}(1-k)\right] \int_{y} m_{l}(y) d y
$$

Subsequently, eq. (7) may be converted into a continuous mass distribution function according to eq. (9):

$$
W^{\prime}(l, y)=W(l, y) \times V\left(P_{0}, y, k\right)
$$

with

$$
V\left(P_{0}, y, k\right)=1+\frac{y(1-k)}{k+P_{0}(1-k)}
$$

This mass distribution function $\left[W^{\prime}(l, y)\right]$, which takes into account the different molar masses of the monomers, is equal to the original Stockmayer distribution function multiplied by a function $V$ dependent on $P_{0}, y$, and $k$.

Similarly, the overall distribution of compositions irrespective of chain length (CCD) is found by integrating over all chain lengths $l$ according to eq. (10):

$$
\int_{l} W^{\prime}(l, y) d l d y=V\left(P_{0}, y, k\right) \times \int_{l} W(l, y) d l d y
$$

The result of the integration is similar to the result of the integration of eq. (5). It also appears that in this case, the distribution function, in which the equality of molar mass is not assumed, is obtained by multiplying Stockmayer's distribution $W(l, y)$ with the same function $V\left(P_{0}, y, k\right)$.

\section{RESULTS AND DISCUSSION}

From the foregoing it appears the mass distribution function, which takes into account the unequality of the molar masses, is a product of two functions. The first function is the original mass distribution function $W(l, y)$, derived by Stockmayer; the second function is dependent on $P_{0}$, the average composition, $y$, the composition deviation, and $k$, the ratio of molar masses.

To illustrate the shape of the Stockmayer mass distribution function $W(l, y)$, a distribution, calculated by means of the original Stockmayer function, is presented in Fig. 1(a and b) for one special case. Here $M_{1}=M_{2}$, $\lambda=400, P_{0}=0.69, r_{1}=0.49, r_{2}=0.38$ are used as parameters of the distribution. To show the effect of the molar mass ratio on the mass distribution it is not very useful to present many examples of the distributions $W^{\prime}(l, y)$. It is, however, worthwhile to present the shape of the function $V\left(P_{0}, y, k\right)$, depending on the parameters $P_{0}, k$, and $y$, since the contribution of $V\left(P_{0}, y, k\right)$ governs the deviation from the original Stockmayer distributions. The results for some selected cases are represented in Figs. 2-5.

If the average composition $\left(P_{0}\right)$ and the ratio of both monomers $(k)$ are assumed to be constant, the function $V$ is only dependent on the composition deviation $y$. The relative difference between the predicted relative mass 


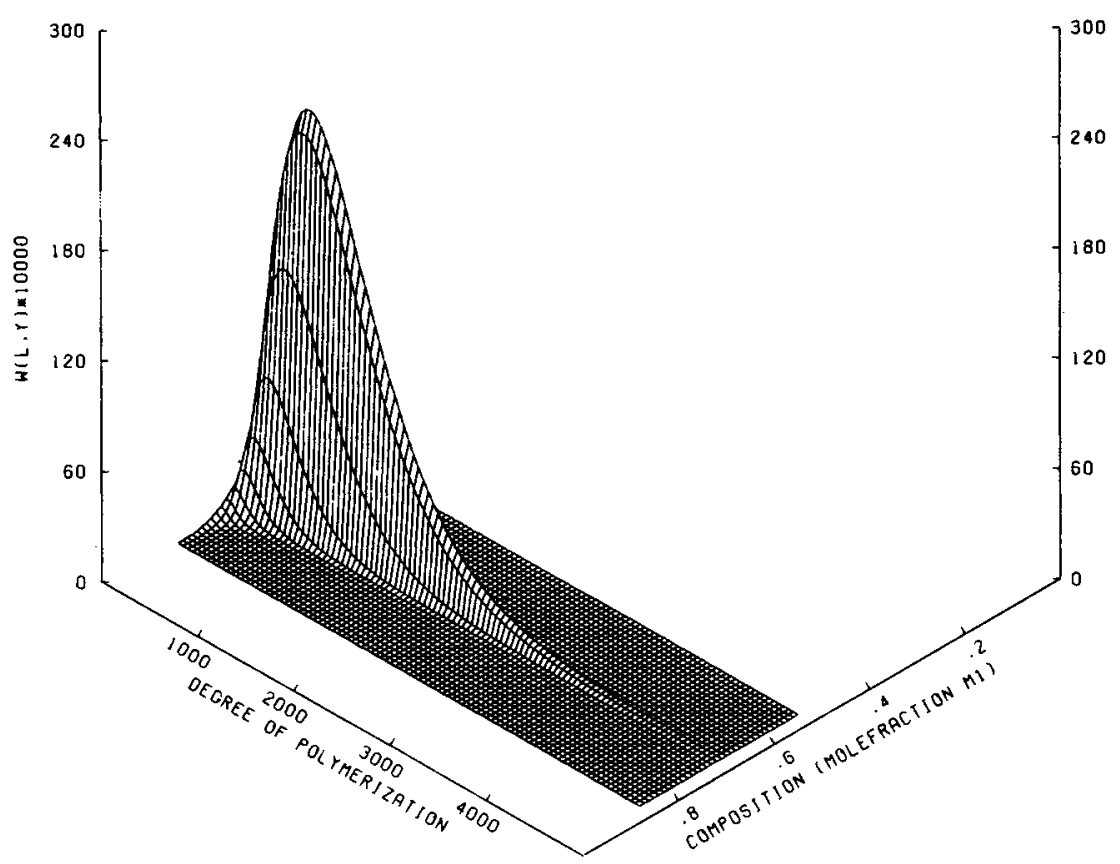

(a)

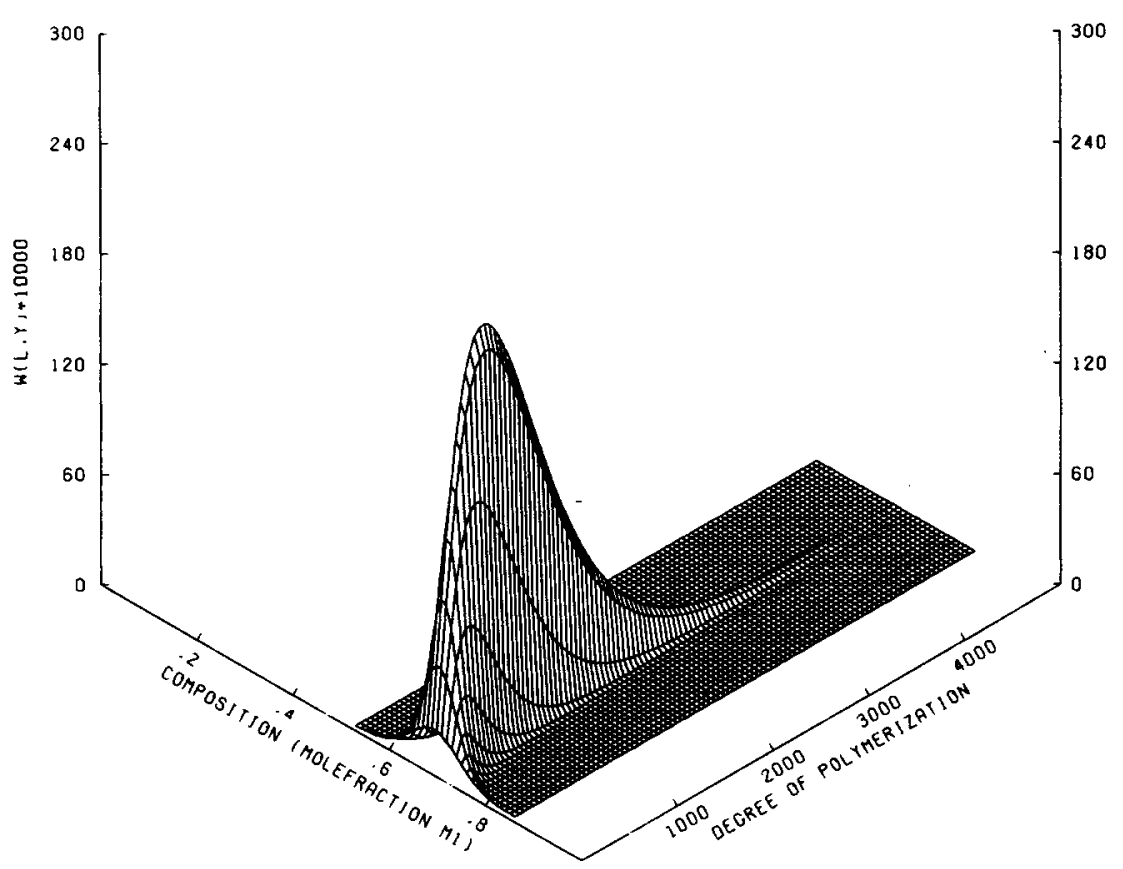

(b)

Fig. 1.(a) Mass distribution of a copolymer according to composition (molefraction $M_{1}$ ) and degree of polymerization, calculated by means of original Stockmayer function. Parameters of distribution: $\lambda=400, P_{0}=0.69, r_{1}=0.49, r_{2}=0.38$. (b) Same distribution as in (a), but the point of view is chasen from the backside. 


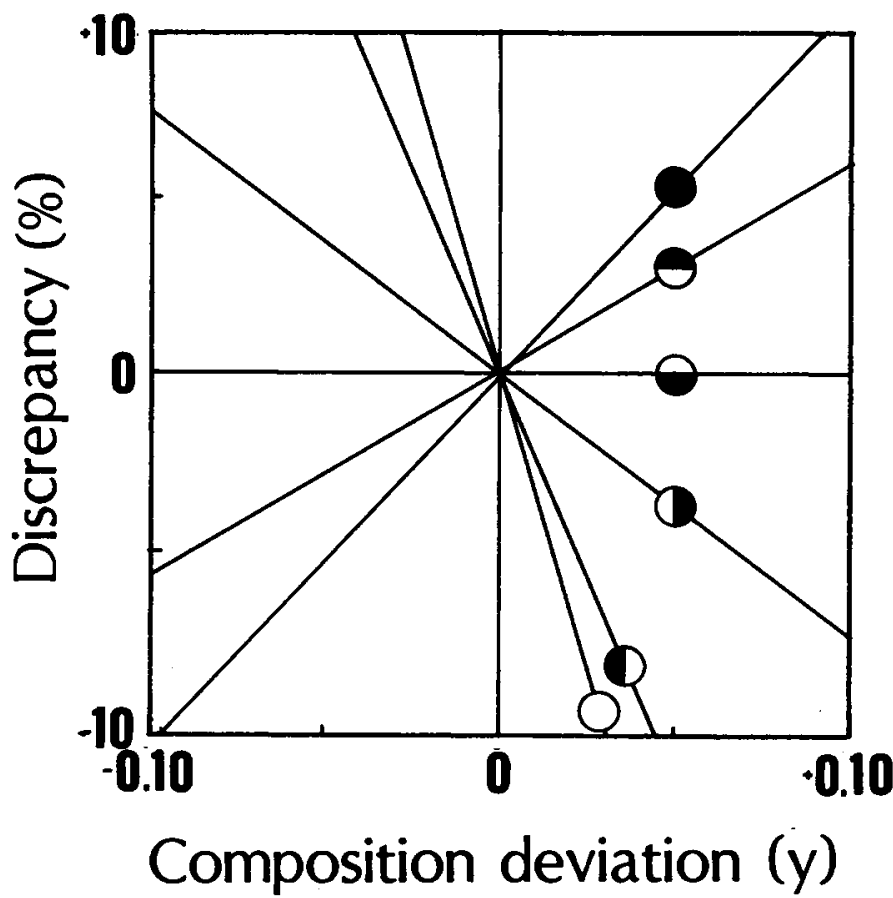

Fig. 2. Effect of composition deviation $y$ (molefraction) on the discrepancy between $W$ and $W^{\prime}(V * 100 \%)$ at constant average compasition $P_{0}=0.60$. (O) $k=10$, (O) $k=5,(\Phi) k=2$, $(\ominus) k=1,(\Theta) K=0.5,(\Theta) k=0.1$.

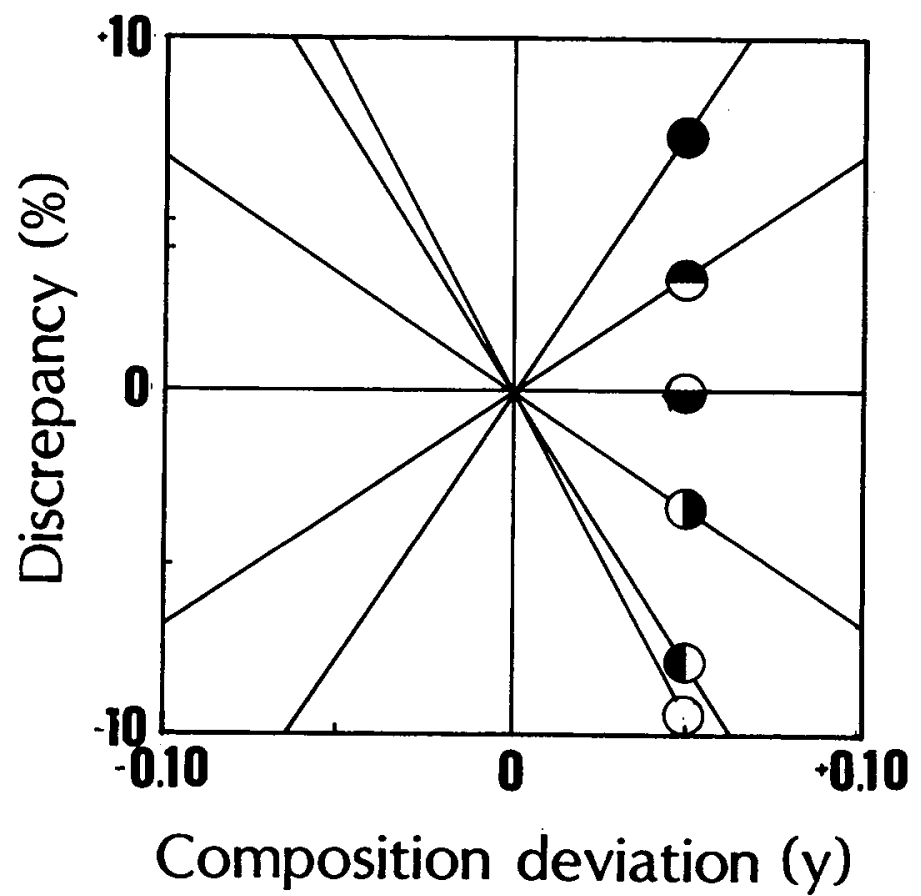

Fig. 3. Effect of composition deviation $y$ (molefraction) on the discrepancy between $W$ and $W^{\prime}(V * 100 \%)$ at constant average composition $P_{0}=0.80 .(0) k=10,(\circlearrowleft) k=5,(\circlearrowleft) k=2$, $(\ominus) k=1,(\Theta) k=0.5,(\odot) k=0.1$. 


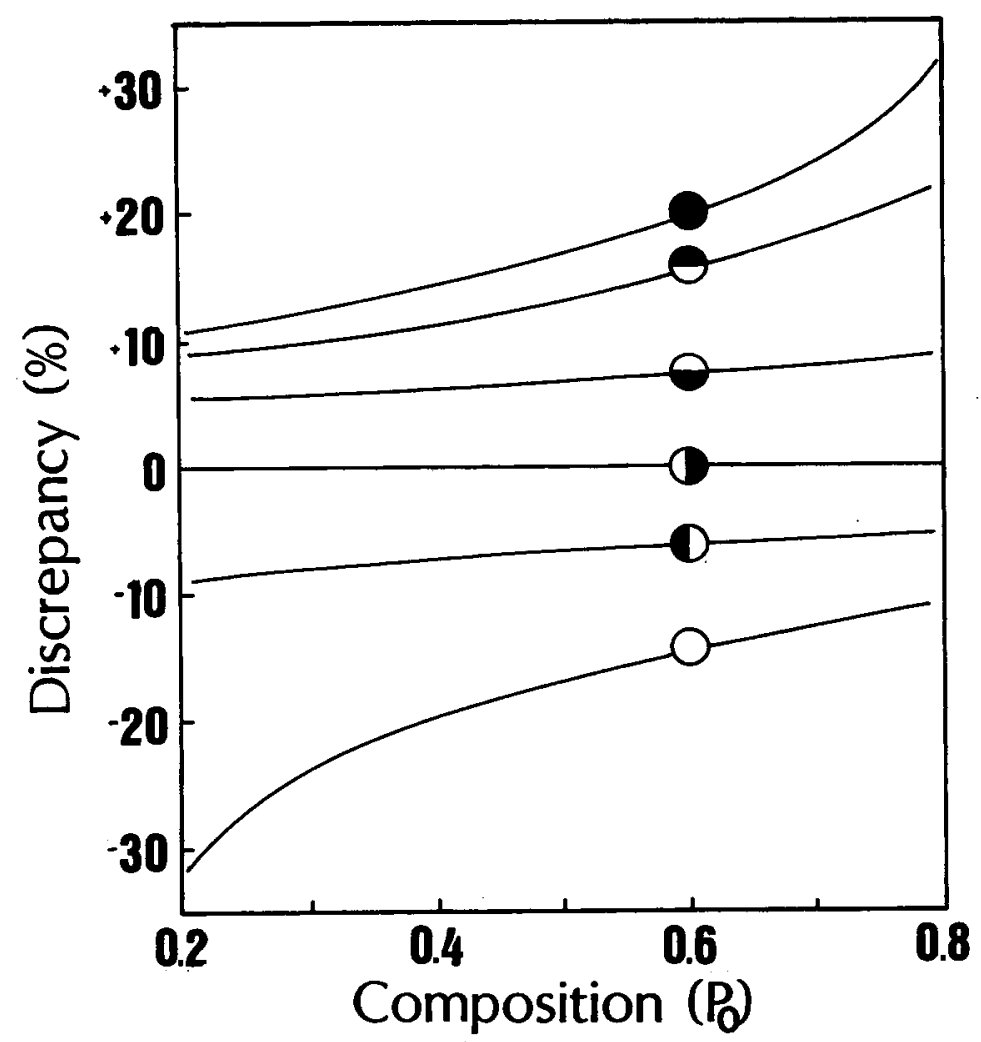

Fig. 4. Influence of average composition $P_{0}$ on the discrepancy $V \times 100 \%$ at constant average compasition deviation $y=-0.1$ and some constant molar mass ratios $k$. (O) $k=0.1,(\bigcirc) k=0.5$, (○) $k=1,(\Theta) k=2,(\Theta) k=5,(\Theta) k=10$.

according to $W^{\prime}(l, y)$ and $W(l, y)$ might be expected to increase when $y$ deviates from zero. This behavior is indeed observed in Figs. 2 and 3. Furthermore, when $k$, the ratio of molar masses of the monomers deviates from 1 , an enhanced discrepancy is also observed.

It should be noted that when $y=0$, i.e., $P=P_{0}$, the relative discrepancy is zero. As a consequence, both mass functions $W(l, y)$ and $W^{\prime}(l, y)$ have the same maximum value $W(l, 0)$ at the same composition $P=P_{0}$. Evidently, when $k=1$, the relative discrepancy is zero $\left[V\left(P_{0}, y, k\right)=1\right]$ and $W^{\prime}(l, y)$ reduces to $W(l, y)$.

Figure 3 also serves to illustrate the aforementioned tendency at another $P_{0}$. Here $P_{0}=0.80$. It appears the relative discrepancy increases when the average composition $\left(P_{0}\right)$ increases from 0.6 to 0.8 , provided $k>1$.

This effect is more clearly illustrated in Fig. 4. In this figure the relative discrepancy is presented as a function of the average composition, assuming constant ratio $k$ and composition deviation $y$. From this figure it might also be inferred that an increased relative discrepancy should be expected in those cases where $P_{0}$ increases from 0 to 1 for $k>1$ and in those cases where $P_{0}$ decreases from 1 to 0 , for $k<1$. The results also indicate an enhanced relative discrepancy as $k$ deviates further from unity.

The influence on the relative discrepancy at some selected average compositions $P_{0}$ and constant composition deviation $(y=-0.1)$ on the ratio $(k)$ is 


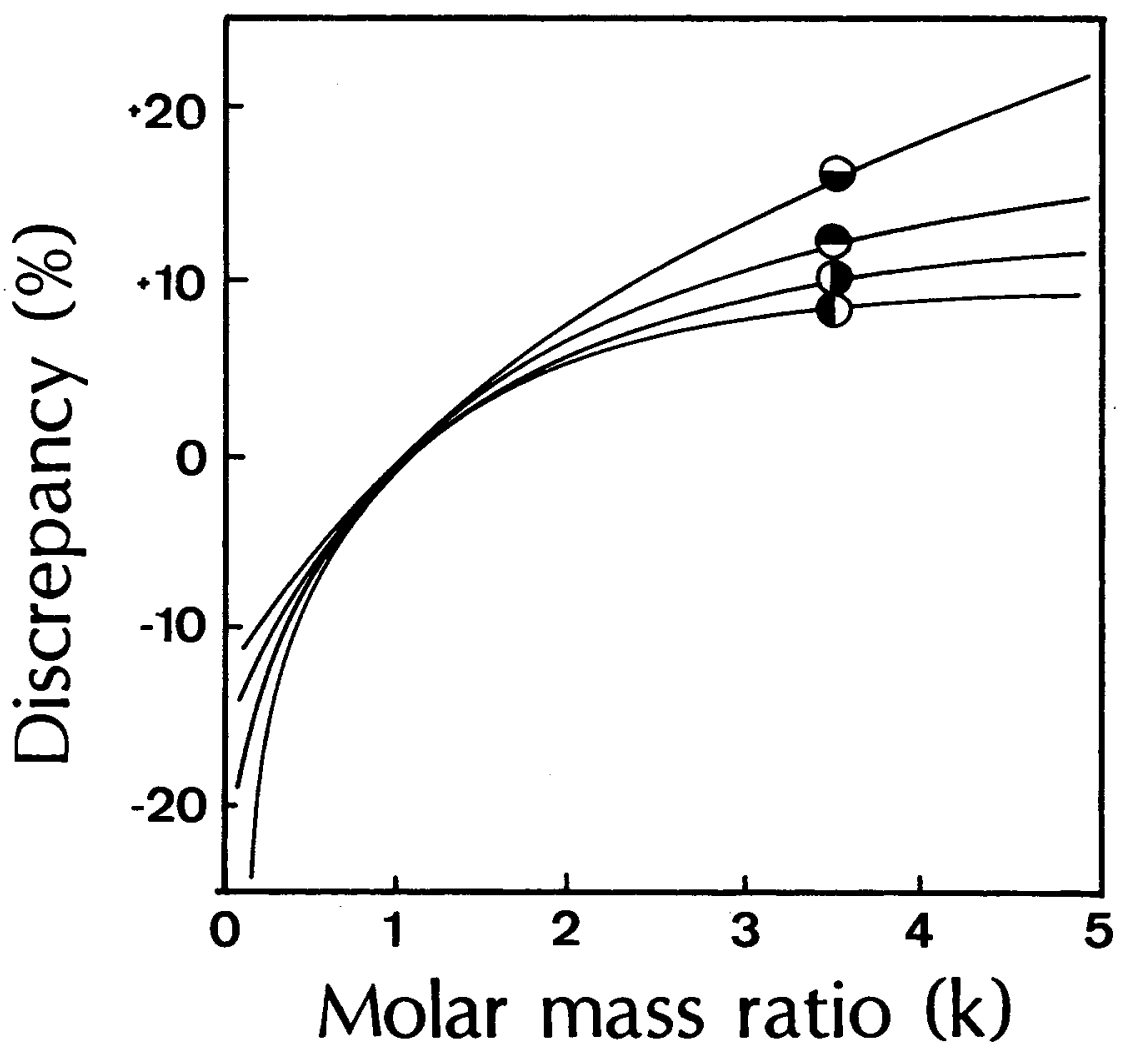

Fig. 5. Relationships between molar mass ratio $k$ and discrepancy $V \times 100 \%$ at constant composition deviation $y=-0.1$ and some selected average compositions. $(\Theta) P_{0}=0.8,(\Theta) P_{0}=$ 0.6 , (O) $P_{0}=0.4,(\bigcirc) P_{0}=0.2$.

presented in Fig. 5. These results clearly indicate an increasing relative discrepancy as $k$ decreases from 1 to 0 or $k$ increases from 1 to 5 .

It should be emphasized that the distribution functions are only valid for infinitesimal small conversion intervals. However, during the course of most batch copolymerization processes, the monomer feed ratio inevitably shifts as the conversion increases. As a consequence, the average composition of the instantaneously formed product also shifts with increasing conversion. In another publication ${ }^{5}$ the total mass distribution is developed for high conversion, with different molar masses of the monomers.

It appears that in many cases the instantaneous distributions presented are not negligible as compared to the conversion distribution. ${ }^{5}$ This emphasizes the need for the present elaboration on the instantaneous distributions.

\section{CONCLUSION}

The presented extension of the Stockmayer distribution functions according to molar mass and composition as well as according to composition irrespective of the molar mass proved very useful in obtaining a reliable prediction of the relative mass of macromolecules with a particular composition and molar mass. 
Our extension of the original theory seems to be a necessity when the ratio of molar masses of the monomers deviates from 1. The discrepancies between the predictions increase when the deviations from the average composicion increase. An enhanced discrepancy is also observed when the average composition $\left(P_{0}\right)$ decreases from 1 to 0 for the ratio of molar masses $k<1$, and when the average composition $\left(P_{0}\right)$ increases from 0 to 1 for $k>1$. The discrepancies also increase as $k$ deviates further from unity.

Our extension contributes to the usefulness and widens the range of applicability of the Stockmayer theory, which becomes important now that experimental methods are being developed ${ }^{3-5}$ to verify the theoretical copolymer distributions.

The authors wish to thank Professor W. H. Stockmayer for valuable discussions and Dr. E. Nies for his useful comments and supportive interest.

This investigation was supported by The Netherlands Foundation for Chemical Research (SON) with financial aid from the Netherlands Organization for the Advancement of Pure Research (ZWO).

\section{References}

1. F. L. M. Hautus, H. N. Linssen, and A. L. German, J. Polym. Sci. Polym. Chem. Ed., 22, 3489 (1984).

2. W. H. Stockmayer, J. Chem. Phys., 13, 199 (1945).

3. G. Glöckner, Pure Appl. Chem., 55, 1553 (1983).

4. G. Glöckner, J. H. M. van den Berg, N. L. J. Meyerink, Th.G. Scholte, and R. Koningsveld, Macromolecules, 17, 962 (1984).

5. J. C. J. F. Tacx and A. L. German, J. Polym. Sci. Polym. Chem. Ed., submitted for publication.

6. J. C. J. F. Tacx, J. L. Ammerdorffer, and A. L. German, Pol. Bull., 12, 343 (1984).

7. S. Teremachi, A. Hasegawa, and S. Yoshida, Macromolecules, 11, 1206 (1978).

8. F. M. Mirabella and E. M. Barrall, J. Appl. Polym. Sci., 20, 581 (1976).

9. E. G. Bartik, J. Chrom. Sci., 17, 336 (1979).

Received October 29, 1985

Accepted January 21, 1987 